\title{
Controle Social e Políticas de Saúde ${ }^{1}$
}

\section{Social Control over Health Policies}

\author{
Aldaiza Sposati ${ }^{2}$ \\ Elza Lobo ${ }^{3}$
}

\author{
SPOSATI, A. \& LOBO, E. Social Control over Health Policies. Cad. Saúde Públ., Rio de \\ Janeiro, 8 (4): 366-378, oct/dec, 1992.
}

As the democratization of health policies develops, social control over public interests has been of help in providing health movements with prominence, not only by denouncing cases of "negligence and omission" by established services, but also by struggling to create regular, favourable conditions by which to exercise control over services and governmental management of public health policies.

In the early 1980s, a remarkable experience occurred in the "Zona Leste" or eastern burrough of the city of São Paulo, consisting of the emergence of Health Councils as a means of popular representation in the control over the state.

Through their analysis of these issues, the authors' intent is to proceed to new problems rather than discussing the make-up of that representation.

Within the political context in the aftermath of the 1988 Constitution, as we are experiencing a new democratic moment and legislation which (in principle) supports people's participation in health policies and defends social rights, then how is the field of social control to be understood? Is it limited to health services or extended to health policy? How do laws move from elaboration to practice?

The text aims to follow issues which arise as social control pushes current conditions towards change.

Keywords: Social Control; Health Rights; Popular Representation; Legal Rights; No Alter

O controle social é, na história de democratização das políticas de saúde, um dos campos que construiu visibilidade aos movimentos de saúde, quer pela denúncia das "ausências e omissões" dos serviços instalados, quer pela luta em construir um espaço regular para o exercício do controle nos serviços e nas burocracias da gestão da saúde. Foi uma experiência marcante, no início da década de 80 , a de criar

\footnotetext{
'O presente trabalho - "Controle Social e Politicas de Saúde" - foi apresentado em uma primeira versāo reduzida como subsidio à Conferência Estadual de Saúde do Estado de São Paulo.

'Pontificia Universidade Católica de São Paulo. Rua Monte Alegre, 984, 05014-001, São Paulo, SP, Brusil.

${ }^{3}$ Núcleo de Investigação dos Sistemas Locais de Saúde do Instituto de Saúde da Secretaria de Saúde do Estado de São Paulo. Rua São Antônio, 590/4a andar, 01314000, Sāo Paulo, SP, Brasil.
}

os conselhos de saúde enquanto representação popular no controle do Estado.

Sem dúvida, pode-se afirmar que esta experiência contrapôs democracia participativa $e$ democracia direta, na região leste da cidade de São Paulo, quando o povo ia às urnas votar em seus representantes no conselho. É interessante notar que até hoje é prática do movimento saber, a cada eleição, quantos votos mobilizou para formar os conselhos.

A partir da Constituição de 1988 e da constituição do Sistema Único de Saúde, a presença da população já deveria ser uma situação posta de saída. Todavia, o processo de democratização não se apresenta do mesmo modo em cada um dos municípios. Permanece a luta pela constituição dos conselhos, pela legitimidade, como da representação popular, pela discussão de sua formação paritária entre população, trabalhadores de saúde e dirigentes. 
Não se pretende, nesta reflexão, um balanço da situação atual, no sentido de voltar a discutir a composição da representação. Busca-se avançar para novos problemas.

O primeiro problema seria quanto à concepção sobre a incidência do controle social: se restrita aos serviços de saúde ou ampliada à política de saúde. $O$ que é entendido como campo do controle social?

$\mathrm{Na}$ conjuntura pós-Constituição de 1988, vivemos um novo momento democrático, isto é, hoje, as leis, a princípio, amparam a participação da população nas políticas de saúde e são, a princípio, defensoras dos direitos sociais.

Todavia temos um novo problema, que é o de fazer com que as leis deixem de ser apenas instrumentos formais, passando à aplicação das mesmas. Esta conjuntura supõe uma nova instrumentação das lutas democráticas e populares, no sentido de se prepararem para a aplicação da lei.

Por terceiro, busca-se mapear questões que se põem quando o controle social se orienta para constituir uma pressão pela mudança/alteração da situação. Em outras palavras, indicam-se as dificuldades, frente ao estilo político brasileiro de exercer a autoridade e fazer política, em se criar um espaço democrático.

A intenção é, portanto, de criar condições para a leitura crítica do controle social, contrapondo a sua versão burocrática a um novo patamar político, como espaço de exercício do protagonismo de sujeitos democráticos populares.

\section{SAÚDE COMO DIREITO E COMO SERVIÇO}

O direito à saúde, defendido na Reforma Sanitária, uraz, intrinsecamente à sua constituição, o apoio, a participação e a pressão dos setores populares.

Em outras palavras, o direito social de ter garantida a condição de saúde de uma população supõe o próprio movimento dessa população em conseguir o reconhecimento e a efetivação desse direito.

Num tom provocativo, cabe perguntar se esta afirmação não contém, em si, uma perversidade, uma vez que exige do sujeito/usuário e, por- tanto, detentor da necessidade, um duplo ônus: além de possuir a necessidade, deve gastar um sobreesforço em criar a solução para atendê-la. No limite do raciocínio da sociedade de livremercado, onde opera o princípio da auto-regulação "fornecedor-consumidor", esta exigência do consumidor seria a demonstração da incompetência da "pesquisa de mercado" em estabelecer as caracteristicas do produto "aos moldes do freguês".

A questão, porém, é muito mais complexa pois, para funcionar na plena lógica de mercado, o "produto saúde" deveria ser uma necessidade de consumo individual, cuja satisfação seria uma questão de gosto e de estilo, e não só de necessidade. Porém, saúde, que é uma questão de vida individual e coletiva, exige um padrão público e social. Isto supõe entendê-la não como um produto a ser consumido, mas, sobretudo, delinear o projeto que se quer como padrão de qualidade de vida de uma sociedade e, nela, de cada um dos cidadãos.

Por mais que queiram transmutar a saúde em produtos consumiveis - sejam medicamentos e/ou tratamentos - ou em mercadorias a compor o imaginário das pessoas, transformando-a em símbolos de consumo, ela é, mesmo que virtualmente, mais do que isso, quer do ponto de vista individual, quer do ponto de vista coletivo.

Saúde é mais do que "uma coisa"; ela é um valor e uma perspectiva: "ter saúde é o melhor remédio", segundo o dito popular. Saúde é direito.

O começo da discussão sobre saúde e controle social necessita tomar distância da armadilha "saúde-consumo", onde o controle é verificar se a mercadoria está adequada conforme o rótulo.

Esta perspectiva supõe "naturalizar" a doença e as carências como coisas que devem acontecer, onde é "normal" ficar doente e consumir um "comprimido de saúde".

$\mathrm{O}$ que se quer dizer é que direito à saúde é mais do que direito ao consumo de saúde. Portanto, direito à saúde é mais do que democratização do consumo da assistência médica, embora esta lhe seja fundamental. Saúde é mais do que "a cesta de serviços", mesmo que públicos, ainda que estes sejam básicos à vida da população. 
Saúde, enquanto tal, não é uma necessidade cujos contomos de sua satisfação estão plenamente dados de saída.

"A saúde define-se no contexto histórico de determinada sociedade e num dado momento de seu desenvolvimento, devendo ser conquistada pela população em suas lutas cotidianas". (Brasil, 1986)

O "usuário/consumidor" é, ao mesmo tempo, um sujeito/democrático virtual na construção da política de saúde, e não um carente a ser atendido por uma instituição transformada em "ofertante de serviços", negadora, em sua prática, dos direitos dos cidadãos.

"Instituir a eqüidade na saúde não se limita a uma mera extensão e distribuição mais adequada dos serviços, mas, igualmente, à sua conformação em um direito". (Cohn, 1992)

No contexto da "Saúde-Projeto-Sociedade", a noção de direito é conquista social. $O$ desafio fica em trabalhar a questão de saúde como direito e como serviço.

Isto não significa tomar estas perspectivas como excludentes. Serviço de saúde é um direito do cidadão, embora saúde, como direito, seja mais do que o serviço de saúde.

É de se ter clara a situação de profunda desigualdade social brasileira e que nela a ausência das atenções sociais é fator de empobrecimento da população. Estamos longe de uma situação de igualdade de acesso a todos, e muito mais longe da eqüidade de resultados dos serviços. O que vivemos é uma situação de alta seletividade e exclusão social.

Portanto, se, de um lado, não se pode afirmar que o horizonte maior da saúde, como direito, são os serviços de saúde, não se pode, porém, pôr de lado tais serviços como constituintes, também, dos direitos dos cidadãos.

Longe de uma situação de abundância e de pleno atendimento em serviços de saúde, a qual permitiria a "cidadania de vigilância", onde os cidadãos vigiam o governo para garantir que os serviços funcionem, Valla e Siqueira (1989) dizem que temos uma "cidadania de escassez" que põe para a população o risco de sobreviver.

$\mathrm{O}$ que é mais interessante, porém, é que este consumidor (individual e/ou coletivo) sofre a lógica de mercado às avessas: paga primeiro pelos impostos, mas não tem o produto, só o direito virtual de atenção e a necessidade efetiva para satisfazer.

Portanto, a participação popular na política e nos serviços de saúde começa, na condição virtual de usuário/cidadão, em participar de uma idéia-projeto para atender a uma ou mais necessidades, na medida em que a necessidade em saúde, como as demais necessidades humanas, é historicamente determinada. O "fornecedor" tem que saber o que passa no plano simbólico "da freguesia" e, nele, qual é a representação da saúde-doença e suas demandas por serviços de saúde.

\section{SAÚDE E DISPOSITIVOS CONSTITUCIONAIS}

O arcabouço jurídico-legal que institui o direito à saúde em nosso país, composto da promulgação da nova Constituição, da Constituição Estadual, da Lei Orgânica de cada município e da Lei № 8080 (Brasil, 1990) e da Lei № 8142, demonstra um avanço no sentido de uma nova concepção da saúde, compreendida como um produto social e histórico condicionado pelas circunstâncias de vida e de trabalho das pessoas.

Convém, aqui, abrir um breve parêntese sobre a Lei $n^{2} 8142$, de 28 de dezembro de 1990, que estabelece as instâncias colegiadas e participativas no campo da saúde: A Conferência de Saúde, que deve se reunir a cada quatro anos, a nível nacional, para avaliar e propor as readequações na política de saúde, e cuja composição envolve diferentes representações sociais; o Conselho de Saúde, como órgão gestor de caráter permanente, com representação dos vários segmentos envolvidos na produção, gestão e usufruto da saúde; o Conass - Conselho Nacional de Secretarias de Saúde; e o Conasems - Conselho Nacional de Secretarias Municipais de Saúde.

A Constituição Estadual do Estado de São Paulo (São Paulo, 1989), no artigo 221, afirma a presença popular nos conselhos estaduais $\mathrm{e}$ municipais de saúde.

No âmbito de toda a legislação, estão contidos dispositivos relacionados à vigilância em 
saúde, à saúde do trabalhador, à descentralização do comando do sistema, ao nivel do território delimitado, e à participação popular e sindical na gestão do sistema, em seus vários niveis.

Apesar de não refletir o conjunto das reivindicações dos movimentos sociais organizados, a atual legislação sanitária está além do que se pratica hoje no sistema de saúde. O legal está mais avançado do que o real, neste aspecto específico.

Em.muitos municípios, trava-se a luta pela formação do Conselho Municipal de Saúde e, nela, o confronto com prefeitos que designam a "representação popular" de acordo com o seu interesse. O conceito de paridade é ainda palco de discussōes enquanto deva preservar os, no mínimo, $50 \%$ de presença popular.

Mesmo reconhecendo que há um avanço, é inegável que há um grande espaço a ocupar, há um vasto campo de ação muito pouco explorado. Particularmente no campo da vigilância em saúde, que engloba as diversas vigilâncias (sanitária, epidemiológica e do trabalhador), há uma defasagem entre o que já está estabelecido como possibilidade de ação e o que se concretiza ao nivel de funcionamento do conjunto do sistema de saúde.

Grande parte das demandas locais pela ação das unidades básicas é quanto à vigilância sanitária, que termina por se transformar em conflito de vizinhos, onde o conselho de saúde se vê na situação de júri popular, ou, então, o assunto vai parar na delegacia do bairro.

A Constituição de 08 de outubro de 1988 (Brasil, 1988), que já tem três anos, não foi ainda regulamentada. Assim, boa parte dos seus artigos não produz efeito imediato na vida dos brasileiros. Pior ainda é que, antes mesmo de ser experimentada, a Constituição é acusada, por alguns, de inflacionária. Cúmplice de construir a utopia de um horizonte melhor para os brasileiros, hoje a Constituição está sendo colocada no banco dos réus, sob a acusação do Governo de que ela "entrava o desenvolvimento nacional".

Apesar destas questões e mesmo sem uma regulamentação específica para a saúde, a Constituição conta com dispositivos que já podem e devem ser acionados nas lutas de saúde, bem como em outras lutas de cidadania.
Os instrumentos constitucionais dos quais a população pode se valer se dão nas três esferas de poder: o Legislativo, o Executivo e o Judi ciário.

\section{PODER LEGISLATIVO}

Os representantes eleitos podem propor projetos de lei no legislativo (Artigo 61, Parágrafo $2^{2}$ ).

\section{Quem os elegeu pode:}

- Participar de audiências para debatê-las (Artigo 58, parágrafo $2 \%$, inciso II).

- Referendar uma lei ou manifestar, em plebiscito, sobre assuntos considerados relevantes pelo Congresso Nacional (Artigo 49, XV).

- Quando organizadas em confederação sindical, entidades de classe ou partido político podem pedir a retirada de uma lei que contrarie o que ficou estabelecido na Constituição (Artigo 103, VIII e DX).

\section{PODER EXECUTIVO}

No chamado Estado de Direito, a Administração Pública está vinculada às estritas previsões legais. Escrava da lei, pode se supor que o povo comanda a Administração.

- Possibilidades de participação direta no Executivo, através de orgãos populares com funções de direção administrativa, como no caso da saúde (Artigo 198, II).

- Legitima a capacidade do cidadão, dos partidos políticos, das associações e dos sindicatos para, fiscalizando a contabilidade, os financiamentos, o orçamento das entidades administrativas, denunciar irregularidades aos Tribunais de Contas (Artigo 74, parágrafo $2^{2}$ ).

- Para não deixar dúvida sobre a obrigação constitucional do encarregado da Administração Pública, define como crime de responsabilidade do Presidente da República os atos que atentem contra o "exercício dos direitos políticos, individuais e sociais" (Artigo 85, III).

\section{PODER JUDICIÁRIO}

Mandado de injunção

- Qualquer pessoa pode pedir ao Juiz para que faça valer o direito criado pelo legislador $e$ não aplicado pelo Administrador (Artigo 50, LXXI). 


\section{Mandado de Segurança}

Impetrado pelo indivíduo ofendido ou pelo partido político,organização sindical, entidade de classe ou associação na defesa de seus membros ou associados (Artigo 5, LXIX e LXX).

\section{Habeas data}

Garantir ao indivíduo o acesso à informação e sua veracidade.

Dentre as poucas leis que foram produzidas, regulamentadoras da Constituição, está o Código de Defesa do Consumidor - o CDC.

Todavia, poucos utilizam o CDC, embora ele estabeleça normas de ordem pública e de interesse social. Portanto, suas regras prevalecem sobre a vontade das partes. A saúde é tratada como prioridade no $\mathrm{CDC}$, quer na perspectiva de relações de consumo, quer na vigilância sanitária (Lazzarini, 1991).

O Código da Defesa do Consumidor é um instrumento que visa garantir as efetivas precaução e reparação de danos patrimoniais $\mathrm{e}$ morais, no plano individual, coletivo ou difuso.

Nesta perspectiva, defende a saúde como proteção à vida e segurança contra os riscos provocados por práticas no fornecimento de produtos considerados perigosos ou nocivos.

Com isto, ele possibilita:

Pelo Artigo $4^{2}-$ quanto às relações de consumo

- a abrangência do conceito de fornecedor significa que qualquer vício (defeito) de qualidade, segurança, quantidade ou inadequação de um produto ou serviço ofertado por um fornecedor público ou privado está sob a mira do $\mathrm{CDC}$;

- racionalização e melhoria dos serviços públicos "adequada e eficaz prestação dos serviços públicos";

- assegura como direito do consumidor o acesso aos órgãos judiciários e administrativos, através da Curadoria de Garantia dos Direitos Constitucionais;

- cria uma série de dispositivos para facilitar esse acesso, entre os quais a facilitação dos seus direitos com a inversão do ônus da prova, a seu favor.
Pelo Artigo 2o - quanto à qualidade do produto

- os órgãos públicos, por si ou por suas empresas, concessionárias, permissionárias ou sob qualquer outra forma de empreendimento, são obrigados a fornecer serviços adequados, eficientes, seguros e, quanto aos essenciais, continuos;

- nos casos de descumprimento, total ou parcial, das obrigaçōes referidas neste artigo, serão as pessoas jurídicas compelidas a cumprí-las e reparar os danos causados;

- os consumidores, através de suas associações, têm legitimidade para representar os direitos dos consumidores perante o poder judiciário. Devem, para tanto, estar constituídos há pelo menos um ano;

- nas ações coletivas, não haverá, o adiantamento de custas, emolumentos, honorários periciais e quaisquer outras despesas, nem condenação da associação autora, salvo comprovada má-fé em honorários de advogados, custas e despesas processuais. Desta forma, fica facilitado o acesso à Justiça para as associações.

Pelo Artigo $10^{\circ}$, Paragráfo $3^{\circ}-$ quanto às ações de vigilância sanitária

- obrigação de informar a população: "sempre que tiverem conhecimento da periculosidade de produtos ou serviços à saúde ou segurança dos consumidores, a União, os Estados, o Distrito Federal e os Municípios deverão informá-los a respeito."

As leis são instrumentos de luta e não só dispositivos formais. Temos que dominá-las para podermos ter mais munição na "batalha da saúde".

A sociedade brasileira decidiu assumir seu próprio governo quando elaborou a Constituição de 1988. Assistiu-se, então, pela primeira vez na história do Parlamento Nacional, à participação das organizações sociais na elaboração das normas fundamentais do Estado.

A tomada da responsabilidade de organizar e dirigir sua vida em sociedade revela-se no artigo que inaugura a Constituição: é ao povo que pertence todo o poder. É ele quem deve exercitá-lo. Para tanto, pode ou eleger representantes ou agir em nome próprio. $\mathrm{E}$ as matérias que devem fazer parte de qualquer constituição que objetive reger uma sociedade no final do 
século XX foram tratadas com essa diretriz. Assim, tanto a organização do governo como o controle do poder econômico e a garantia dos direitos das pessoas, consideradas individualmente ou na coletividade, permitem, na expressão constitucional, a atuação imediata do povo, fonte de todo o poder.

Diversos mecanismos foram indicados para provocar a participação popular na gestão do Brasil. Uma destas vias, mais tradicional, são os mecanismos formais de democracia representativa, isto é, através dos representantes parlamentares - vereadores, deputados e senadores -, uma vez que a Constituição ampliou o poder do Legislativo face ao Executivo.

A segunda via, na qual a área de saúde teve forte contribuição pela experiência, é a da democracia participativa e democracia direta, através da presença de órgãos populares junto ao Executivo, operando o controle e a fiscalização das ações do Governo, tarefa esta que é estendida a sindicatos, partidos e demais organismos sociais.

A terceira via, através do Judiciário, possibilita, a princípio, que qualquer pessoa faça valer o direito criado pela legislação e não aplicado pela administração.

A presença da participação popular diretamente no Executivo tem levado, inclusive, à construção da concepção de que o quarto poder é o poder popular na ação de Governo e de Gestão.

Sem dúvida, a Constituição amarrou a consagração dos direitos ao que se pode denominar "burocracia jurídica e do Judiciário". Todavia, este segmento do Estado não passou ainda por uma "reforma" capaz de pensá-lo e operá-lo num ritmo compativel com o seu papel assegurador da democracia. Isto não deve, porém, intimidar a sociedade. Pelo contrário, é colocando-se de frente a esta instância de poder que conseguiremos alterá-la, vale dizer, desburocratizá-la em defesa da democracia.

Saúde é direito de todos na norma constitucional, todavia não tenha sido, ainda, direito reclamado no tribunal: direito que não entra na justiça é direito simbólico, e não direito de fato.

O Governo não está aprovando as leis de regulamentação da Constituição. Portanto, o controle social na saúde, como direito, tem como primeiro ponto de pauta a própria regula- mentação da Constituição quanto ao direito à saúde.

Isto significa entrar em rota de colisão com o estilo tradicional de fazer política no Brasil, onde as decisões não são tomadas na esfera pública, ou onde não ocorre uma "regulação social pública".

No Brasil, o estilo político tradicional é de resolver as situações caso a caso e, de preferência, no interior dos gabinetes, e não de forma clara, global, transparente e pública. Assim, a efetiva universalização da saúde e, nela, a eqüidade de resultados são alguns dos grandes desafios que supõe muita luta democrática da sociedade.

Emtıra o discurso constitucional ecoe na voz de governantes e de dirigentes públicos e expresse, sem dúvida, o avanço de uma vontade política, esta vontade política não-regulamentada se transveste em "vontade de políticos", onde cada caso é um caso. Na ausência de lei federal regulamentadora do direito à saúde, ocorre o que Oliveira (1990) chama de "regulação truncada", onde existe, simultaneamente, a ausência de regras estáveis e a ausência de direitos.

Cabe aqui uma rápida indicação - já que não é área de nossa especialidade profissional - quanto à superação da concepção política de direito, na direção de construção do direito coletivo capaz, inclusive, de inaugurar a dimensão coletiva da cidadania. Seriam os direitos de grupos sociais, o direito comunitário gerando a defesa da responsabilidade social pelas condições de vida construídas para a população. A exemplo, uma auditoria da dívida externa brasileira poderia culpabilizar responsabilidades? De quem?

A ausência de uma explícita regulação na direção da universalidade do direito - e não mera isonomia que não capta a heterogeneidade do real - faz com que a política do favor, da clientela, prevaleça à política do direito, ou, em outras palavras, com que não se tenha certeza ou garantias prévias; tudo vai depender do interesse de quem vai atender, não há padrões antecipados. Quando se consegue entrar, não se sabe em que condições de atendimento se vai sair.

Mas não se trata só de "vigiar o serviço", pois o trato do resultado é negócio a ser tratado antes de começar o serviço: quem não diz o que 
quer de começo acaba recebendo o que não quer ao final.

Como depende do interesse e do estilo de governar de quem está no governo e, sem dúvida, da tecnoburocracia, o avanço político da política de saúde, bem como das demais políticas sociais, é uma "coisa que vai e vem", não tem garantias de continuidade.

Neste quadro flutuante, o controle social encontra um campo quase ilimitado de ação.

No estilo brasileiro pouco democrático de construção das políticas e decisões, a regulação do Estado é feita sem a esfera pública, isto tanto nas políticas sociais como nas econômicas. A ausência da esfera pública significa a utilização do fundo público, do dinheiro público, de forma casuística - sem regras gerais, sem um projeto transparente e sem a presença dos interesses divergentes - ao serem tomadas as decisões.

Em outras palavras, as decisões dos dirigentes públicos - incluindo os técnicos - são tomadas para atender aos interesses dos que têm mais influência, na maioria das vezes favorecendo os interesses de quem está no poder.

As decisões se dão na base de "conchavo", convocando apenas diretamente o interessado, como diz Francisco de Oliveira: "é a regulação ad hoc, que opera num vazio de alteridade". Isto é, sem a presença do outro, ou dos outros interesses e interessados (Oliveira, 1990).

Se o assunto é decidido em petit comité entre os mesmos, como pode ocorrer a vigilância do controle social? Nesta situação não-transparente, o que acontece é a denúncia da exclusão, do não estar presente, do não ser chamado; é a denúncia do uso dos recursos para favorecer alguns.

A democracia brasileira já permite, a nível legal, o direito pelo menos da reclamação pública, embora, em algumas cidades, como Canapi, "quem fala leva tiro". A Constituição garante estes direitos. A questão agora é colocá-los em prática.

A cultura política brasileira ainda convive com o fenômeno do coronelismo, que sujeita a população ao poder dos proprietários, donos da política local. Sob coação e medo, só é dito o que se quer ouvir; é a anulação da vontade de si. É a herança patrimonialista.

A barbárie antidemocrática também se trans- veste de populismo, onde direitos se transformam em doações e favores. Em uma carga cultural paternalista, as ações são bondades dos governantes ou exercicio de clientelismo. Nessa situação, instaura-se uma espécie de negócio, de troca, entre o eleitor (de fato ou potencial) e o representante político, que busca salientar o caráter individual da conquista. É uma cumplicidade onde "eu the atendo porque você é um dos meus".

Privatizado o Estado nos recursos, no fundo público e na política, como se dão a presença popular e o controle social?

\section{SAÚDE, REPRESENTAÇÃO POPULAR E CONTROLE SOCIAL}

Estas rememorações da política brasileira permitem colocar a discussão do controle social não em um patamar burocrático, mas sim em um patamar político.

Não se trata de "vigiar uma burocracia", ainda que, imediatamente, a relação seja a do usuário com o hospital, com a unidade básica, com a fábrica, com uma diretoria. O que está em questão é criar uma nova cultura política/democrática que, ao democratizar as decisões, traga $a$ alteridade.

Este conceito de alteridade, ou da presença do alter - o outro, emprestado da psicologia quer marcar a distinção das situações onde estão presentes sempre os mesmos. Um e outro são sujeitos, portanto, protagonistas de decisões e de ações. O que se quer marcar é a presença de um sujeito que se contrapõe, que tem força e presença para pressionar e ter protagonismo, isto é, ser sujeito, e não sujeitado. Não se trata de simplesmente mais um, mas da presença de um pólo de representação que tem capacidade, pela sua posição histórica e social, de se contrapor àqueles que detêm o poder institucional. $\mathrm{E}$, mais do que um adjetivo, como representante "popular" ou uma "nova" representação, ter uma inserção substantiva na construção coletiva do direito à saúde.

O conceito de alteridade, pelo seu carátersubstantivo, permite o significado da oposição em presença. Resta indagar como tomar parte e partido nesse processo de construção do direito à saúde. 
A organização da representação popular em conselhos é, sem dúvida, um avanço, mas um avanço face ao autoritarismo do passado. É necessário estender o poder da representação popular à construção e gestão da política de saúde.

A presença popular não é "estilo populista de esquerda", ou ideário de sanitaristas ou de assistentes sociais "que adoram uma reuniãozinha". E direito de tornar o Estado efetivamente coisa pública. É desprivatizar interesses. $\mathbf{E}$ introduzir "cenas de negociação explícitas".

Todavia, a alteridade não é igual à presença física das pessoas, dos representantes. Estes têm que ter a capacidade de influir, de se contrapor, o que significa ter informações, ter opinião, na perspectiva da defesa de interesses coletivos.

Em outros termos, as representações têm que dominar as condições, os instrumentos, para serem de fato protagonistas, sujeitos da ação, e não meros complementos.

Um dos efeitos nocivos da democracia participativa vivida na Nova República foi a doença do partipacionismo, que terminou transformando o "povo" em coisa que se põe na reunião, na assembléia, etc. $O$ "povo" virou munição para os dirigentes conseguirem verbas nas lutas de orçamento; o "povo" é a moeda para alguns ganharem força. Em outras palavras, o "povo" vira uma presença que preenche espaços, mas que é congelada em sua capacidade de autoria histórica.

Sem dúvida, ainda necessitamos de muitos momentos de presença de massa para podermos tocar a sensibilidade das pessoas. A exposição pública e explícita da exclusão faz-se necessária face à trivialização da questão social no Brasil, embora hoje a sociedade-espetáculo já exija manifestações mais elaboradas, como a dos bancários, que, uniformizados ensajaram uma partida de futebol durante a sua greve. Ou a dos ecologistas, que, em Angra dos Reis, criaram cenas de acidentes automobilísticos como forma de protesto.

O que se quer salientar é a compreensão da presença popular na política de saúde, na condição de uma exercício de democracia direta. $O$ controle social é, a princípio, uma forma de interlocução regulada e institucionalizada que já tem um considerável grau de aceitação de legitimidade.

As novas questões se colocam, portanto, em como se dá esse controle ou em quanto ele se tem tornado um efetivo exercício democrático. Não basta indagar se o controle social melhora os serviços de saúde.

Esta maneira de colocar a questão transforma a relação social que se estabelece entre as representações do Estado e da sociedade civil, como espaço de controle social, em um ajuste funcional e burocrático. Talvez uma pergunta melhor fosse: qual o grau de apropriação popular das políticas e açōes de saúde a partir do controle social?

É interessante, por exemplo, darmo-nos conta do domínio da política de saúde por alguns antigos militantes dos movimentos de saúde. Seguramente, muitos são interlocutores bem mais capacitados do que vários dirigentes.

O espaço do controle social, ainda que institucionalizado, não é meramente administrativo; é um espaço político que põe em cena interesses, imaginários, representações. Este espaço é uma situação de partida, e não de chegada.

É neste contexto que se entende que, a princípio, o exercício do controle social é espaço de criação de uma cultura política democrática. Todavia, esta intenção, ou "idéia perspectiva", se defronta não só com a cultura elitista $\mathrm{e}$ burocrática dos "animais institucionais", mas também com a tradicional cultura casuística e tutelar, que busca reduzir cada situação a um caso particular.

O conceito, que se levantava há pouco, de alteridade, enquanto capacidade de exercício do protagonismo na defesa de interesses que se contrapõem ao estabelecido, passa a ser útil mais para mostrar a sua negação do que a sua afirmação em nossa realidade.

\section{Controle Social e a Alteridade Negada}

O controle social, como uma operação química que mistura vontades e interesses, vai apresentar resultados dos mais explosivos aos mais insossos.

A alteridade cooptada é um deles e ocorre em dois sentidos: primeiro pela fragilidade da representação que não possui informação $e$ 
capacidade argumentativa, e, portanto, pouco opina; segundo, pela prática da cumplicidade, que ao incluir o interesse restrito e imediato dos representantes populares, afasta-os da luta pela atenção mais ampla dos representados. Esta questão abre a necessidade de se instalar uma política de informação que não seja mera transmissora, mas polemizadora de questōes, equivale dizer, capaz de problematizar, argumentar e formar opinião.

A alteridade subalternizada, onde a relação é de deferência de quem tem o poder pela "visita que chega". O espaço não é do alter, mas dos "donos do poder". O grande risco é a infantilização, tratando os representantes populares como crianças do pré-primário. Reduzem-se os assuntos, é retirada a sua complexidade, desproblematizam-se as questões, pois " o povo não iria entender". Na verdade, é a reiteração da cultura elitista, onde o "povo" é visto como ignorante, digno de comiseração. É claro que isto não significa o domínio popular da linguagem técnica dos "entendidos". Supõe esta perspectiva a decodificação dos temas em um modo de falar que não provoque o ocultamento das questões. Enfim, ter um programa que traduza para todos entenderem.

A alteridade tutelada, uma variante da subalternidade. Esta forma é, em geral, exercida pela tecnoburocracia. Muitos segmentos técnicos que se entendem identificados com os interesses populares terminam por ocupar o espaço da interlocução para si, criando um vazio de alteridade popular por "advogar a causa" e tomar o lugar do "alter popular". Francisco de Oliveira (1990) salienta que os segmentos médios, através de suas organizações ou de ocupação de espaços nas organizações sindicais e sociais, tendem a se transformar no "superego", ou em um falso alter, do Estado, transformando a oposição menos ideológica e mais programática. Nesta redução burocrática, a vigilância é empobrecida para o controle do "cumprimento de medidas mensuradas pelo metro da competência técnica dos agentes técnicos da não-esfera pública".

Estes estilos de relação acabam por consagrar uma democracia conservadora onde os "álteres" ficam numa condição de "quase-sujeitos políti$\cos ^{\prime \prime}$ e não alteram a forma de "regulação truncada", ou caso a caso. Aumenta o número dos que se sentam à mesa, mas ainda não repercute aquilo que se discute à mesa para os representados.

Alguns dirigentes consideram ofensivas as reuniões de portas abertas, gravadas, com presença da imprensa, etc. $O$ estilo Juruna, motivo de múltiplas piadas, é, na verdade, a tentativa de proteção ao conchavo, na perspectiva da direção da regulação caminhar para a esfera pública.

A direção de "democracia avançada", no campo do controle social, é, portanto, a introdução de mecanismos, estilos e relações que rompam com a cultura casuística.

Por sua vez, esta ruptura toca na questão do compromisso com o decidido, como também da garantia de continuidade das decisões. Isto põe dois problemas: a institucionalidade e a complexidade das questões.

\section{Saúde e Novas Exigências para o Controle Social}

A luta dos movimentos de saúde, no princípio dos anos 80, marcava a discussão da clara autonomia popular dos conselhos de saúde frente à organização estatal. A questão do reconhecimento do movimento popular como um interlocutor legítimo, devidamente identificado e reconhecido, exigia a presença de um médico, do chefe, nas reuniões do conselho. Era buscado um vínculo na burocracia do Estado que, todavia, não subordinasse a representação popular e a distinguisse dos organismos transclassistas, como clubes de serviços, lideranças tradicionais instituídas, etc.

Conquistado o patamar de interlocutor privilegiado de saúde, o movimento social teve melhor caracterizada a sua autonomia. Todavia, o processo decisório interno dos organismos do Estado, das burocracias de saúde, introduziu outras questões, como a democracia interna e a participação de funcionários nas decisões sobre a gestão de saúde.

A questão do envolvimento dos trabalhadores de saúde evidentemente traz outros elementos, como, o interesse das corporações, o ponto de vista de quem opera os serviços de saúde, e não só o de quem os dirige. É fato, também, que a produção de serviços de saúde, na perspectiva democrática e de consagração de direitos, passa 
não só pela cultura política autoritária, tutelar e clientelista de dirigentes, mas dos próprios trabalhadores de saúde.

Não basta o avanço virtual da norma em considerar a saúde como direito. A cabeça, o modo de pensar, as representações, o imaginário dos trabalhadores de saúde - estes são os que dão forma a tais direitos à população ao atendê-la no balcão, na consulta ou na portaria.

Como prefigurando um "Estado paralelo", é na dinâmica do funcionamento dos serviços que, concretamente, a população vive a relação governo-população e constrói o seu conceito de direito - ou não - à saúde. O direito não se realiza de imediato. A representação do trabalhador da saúde e de seus interesses é uma mediação que circula na realização concreta do direito.

Portanto, a forma de regularização e de normatização da presença popular na gestão de saúde indicou o caminho tripartite, envolvendo os trabalhadores de saúde, os dirigentes e a representação popular.

$\mathrm{Se}$, no começo da década de 80 , as representações dos movimentos lutavam pelo seu reconhecimento como interlocutores das necessidades populares, ao final da mesma esta luta foi legitimada e "normalizada". Como tal, não é mais inusitada, ou não é uma presença clandestina devido à adesão deste ou daquele chefe mais progressista ou mais democrático.

Todavia, a indagação é se esta legitimidade deve ser legalizada e institucionalizada e como trabalhar as questões decorrentes de uma possível institucionalização.

Uma questão se refere à relação instituído-instituinte. $O$ movimento social não deve se transformar em uma "personalidade jurídica", sob pena de reduzir sua particularidade e sua capacidade de interlocução a mais uma das "entidades ou organizações sociais". É próprio do movimento a sua capacidade instituinte.

Todavia, o Conselho de Saúde, que não é, nem pode ser, o movimento, ainda que deva com ele manter uma relação orgânica, necessita ser institucionalizado a fïm de constituir "uma regularidade" no fluxo decisório da instituição. Em outras palavras, necessita constituir um sujeito coletivo regular ou contínuo, com delegação de autoridade para poder influir na gestão e produção das políticas de saúde.

Esta situação de regularidade traz mudanças nas relações, pois o Conselho, em ação, deve ser a própria construção do espaço democrático, do espaço de influência.

O funcionário, que, às vezes, era um "interlocutor clandestino", virou "interlocutor oficial". Podemos dizer que o Conselho de Saúde, que era oposição, virou situação. $O$ grande risco nesta nova institucionalidade é o de se transformar em mais uma burocracia.

Outra questão da "prova de institucionalidade" poderia ser simplificada destacando-se o seu caráter adjetivo ou substantivo. Em outras palavras, o que se pōe em questão é a manipulação dos dirigentes em fazer do "espaço de construção democrático palco de jogos de cenas populistas", e não de efetivos espaços de influência democrática.

Não basta criar conselhos, comissões, comitês; é necessário estabelecer a forma pela qual estes influenciam as decisões institucionais.

Isto significa dizer que o controle social, para ser exercido de fato, precisa não só de informações, mas de regularidades organizacionais.

Através destas regularidades organizacionais, pretende-se colocar em questão o grau de democratização interno das organizações de saúde, que demarca o fluxo do processo decisório e o grau de influência de cada instância ou unidade de organização na gestão institucional. Os momentos de reunião dos conselhos não podem ser simples conversas que não penetram a instituição. É necessário ter claro o canal, ou canais, pelo qual ocorre a interferência na dinâmica da instituição, seja um hospital, uma unidade básica, uma diretoria, uma empresa, etc.

Para que o controle social seja, de fato, um espaço de alteridade, é necessário que o espaço institucional onde ele interfere seja, de fato, um espaço de regulação, e, ainda mais, exige-se que a instituição defina sua política de regulação; caso contrário, teremos uma "íntima regulação ad hoc". Um exemplo disto são as situações em que só alguns assuntos é que vão para o Conselho, ou para o território da alteridade. Ou, ainda, no difuso sistema decisório da instituição, não fica claro quem é que vai dar 
conta, na divisão do trabalho institucional, de fazer acontecer aquilo que foi decidido. Afinal, quem faz acontecer o que se discute?

$O$ que se quer assinalar é que o controle social, ao provocar a democratização da instituição, provoca, ao mesmo tempo, a necessidade de que esta tome claro o campo da sua organização interna, sua divisão de trabalho, seus responsáveis.

A democracia exige a introdução do planejamento. A gestão coletiva e democrática se confronta com a "gestão happening" e casuística. Ainda que possa parecer aparentemente uma contradição, democracia não combina com laissez-faire. Ela supōe organização, definição de atribuições e de responsabilidades.

É possível que tenha ficado mais claro ao movimento discutir e cobrar as ações quando o Estado estava sob governos autoritários, que demarcavam com quem estava o poder, em geral centralizado, do que nos estilos de gestão soft, ou pretensamente democráticos, que, ao diluir a autoridade, por entendê-la autoritária, constróem uma fluidez que não demarca os territórios de decisão. Esta é a falsa descentralização, que desconcentra ações, mas não poderes.

A construção democrática é mais palco de uma relação de conflito do que de consenso, o que não é fácil nem de se admitir nem de se enfrentar.

Estas considerações, ainda que pontuais e simplificadas, sobre a institucionalização do controle social já mostram elementos do segundo problema, posto na ruptura da cultura casuística das organizações prestadoras de serviços públicos: a complexidade.

$O$ que se pretende delinear com o conceito de complexidade é o convívio de múltiplos sujeitos e interlocutores na construção democrática.

Esta interlocução coletiva supõe uma pedagogia de trabalho pautada no conflito, nos jogos de negociação.

Por outro lado, esta complexidade também advém dos múltiplos sujeitos - estatais que operam o sistema de saúde.

Uma das decorrências negativas desta multiplicidade é a prática do jogo do alheio: "isto não é comigo, é com ele", ou com o outro, em geral, o ausente.

Compōem este jogo do alheio as outras duas usuais saidas: mas o "buraco está mais em baixo", ou "é muito complicado". As explicações que levam a um grande conformismo e sentimento de incapacidade de mudar.

Sem dúvida, as questões conjunturais são reflexos de uma estrutura econômica fundada na profunda e perversa desigualdade econômica e social da realidade brasileira. Todavia, o segredo está em como tocar a estrutura pela conjuntura, que é a sua forma concreta, ainda que aparente, onde se pode atuar no cotidiano.

No "jogo do empurra" de uma instituição para outra, termina sendo reproduzido o jogo dos guichês da burocracia, que vai irresponsabilizando os funcionários, um a um.

$O$ que se quer chamar a atenção é que o "jogo do alheio" pode ser uma tática de ocultamento das próprias responsabilidades.

A complexidade da construção democrática não pode, todavia, ser uma barreira que acabe por sustentar "o ocultismo" como "religião do poder".

\section{O Controle Social em Questão}

Esta reflexão buscou demarcar alguns pontos sobre o controle social.

- Primeiro, o controle social supõe um padrão de representatividade na construção, operação e gestão das políticas sociais, em específico as de saúde.

A representatividade deve ter a capacidade de se contrapor, influir ou assumir efetivamente seu poder de alter. Num jogo de palavras, essa alteridade deve ter poder de fazer alteração, entendida desde barulho até mudança.

- Segundo, o controle social deve corrigir as lacunas da democracia representativa, introduzindo novos sujeitos democráticos/populares, ampliando, ao mesmo tempo, a democracia política e a democracia social.

A forma coletiva como se organizam os movimentos $\mathrm{e}$ as representações de saúde permite construir a "idéia - possibilidade" de se superar o exercício da democracia representativa nos limites do Estado de Direito para formas de democracia direta, exercitando a 
construção popular da democracia, que é uma exigência à sociedade brasileira, tradicionalmente autoritária, elitista, paternalista e clientelista no seu estilo de fazer política.

- Terceiro, o controle social é a possibilidade de ruptura da "regulação truncada" e espaço possível da constituição dos caminhos da "regulação na esfera pública".

O controle social é a possibilidade de romper com o caráter privatista, de favorecimento a alguns. É um exercício de trazer as questões e as decisões para mais interlocutores, como já foi dito, para cenas explícitas de negociação. Assim, o controle social, mais do que fiscalização, pode constituir espaço de "câmaras de negociação".

- Quarto, a relação social fundadora dos espaços de controle social deve estabelecer regras - até para serem modificadas no avanço da experiência - que definam espaços de influência.

Não se pode ser conivente com a transformação do espaço do controle social em uma continuidade burocrática de reuniões, onde não se tem compromisso com os resultados e efeitos. O exercício da alteridade supõe, como já dito, causar alteração.

- Quinto, o controle social necessita ser institucionalizado, tornar-se visível, de modo que alterações em sua continuidade possam tornar-se públicas.

As práticas de tornar públicas as ações e decisões para os representados, para a instituição, são fundamentais para ampliar a própria força deste controle.

- Sexto, o controle social deve incidir não somente sobre a eqüidade dos resultados, mas também sobre a igualdade do acesso.

Como se disse no princípio, o grande risco é transformar a saúde como serviço, esquecendose da saúde como direito. Ou transformar o controle social em mecanismo de regulação para os serviços existentes, isolando-o do horizonte do que ainda deve ser feito para garantia do direito à saúde a todos.

- Sétimo, o controle social deve dizer respeito aos serviços públicos e privados, como também, e principalmente, às atenções não só aos serviços básicos, mas à política de saúde do trabalhador.

Ainda que se traga maior experiência da presença popular nos serviços públicos de saúde, como exigência das lutas sociais, com isto secundarizando as lutas sindicais de saúde do trabalhador e a relação de controle dos serviços privados de saúde, o que, aliás, este documento não conseguiu superar, é necessário abrir este campo de integração de lutas e de experiências de controle social.

Postas estas questões, cabem os encaminhamentos ou a indicação dos aliados possíveis neste processo de ruptura da regulação truncada das políticas sociais, efetivando o direito de fato, ou, como diz Amélia Cohn, a "cidadania ativa na democracia social brasileira" (Cohn, 1991).

\section{Alianças e Encaminhamentos}

Uma das alianças é a que provém do próprio acúmulo do conhecimento, da análise das práticas e das experiências. Aqui, um destaque para o núcleo Participação e Saúde/ CEDEC, que vem emitindo boletins regulares sobre as conclusões parciais da pesquisa "Cidadania e Políticas Públicas", que tem por base o caso de São Paulo na gestão 89/92.

Outra aliança é a de somar os avanços do controle sindical na luta pela saúde do trabalhador com as formas de controle da política de saúde pública.

A aliança entre as formas institucionais de controle do governo e de gestão com os movimentos sociais, não permitindo a burocratização das questões pelas representações populares instituídas.

A aliança da política de saúde com questões mais gerais, tanto no que se refere ao padrão de proteção social do cidadão brasileiro como ao projeto de reforma do Estado, na busca de uma 
ordem democrática e de uma sociedade justa, pressupõe que se transforme a lógica de regulação própria das políticas sociais em mecanismos de emancipação de uma ordem social predadora.

\section{RESUMO}

SPOSATI, A. \& LOBO, E. Controle Social e Políticas de Saúde. Cad. Saúde Públ., Rio de Janeiro, 8 (4): 366-378, out/dez, 1992.

Na história de democratização das políticas de saúde, um dos campos que construiu visibilidade aos movimentos de saúde, quer pela denúncia das "ausências e omissões" dos serviços instalados, quer pela luta no sentido de construir um espaço regular para o exercício do controle nos serviços e nas buroctacias da gestão da saúde, foi o controle social da coisa pública.

No início da década de 80 , a experiência marcante na região leste da cidade de São Paulo foi a de criar os conselhos de saúde como representação popular no controle do Estado.

Nesta reflexão, as autoras não pretendem discutir a composição da representação, mas sim avançar para novos problemas.

Na conjuntura pós Constituição de 1988, vivemos um novo momento democrático. As leis, a princípio, amparam a participaçāo da população nas políticas de saúde e são defensoras dos direitos sociais. Como, então, é entendido o campo do controle social? Este restringe-se aos serviços de saúde ou é mais ampliado, englobando a política de saúde? Como é que as leis passam da sua formulação para a sua aplicação?

Busca-se, no texto, mapear questões que se colocam quando o controle social se orienta para constituir uma pressão pela mudança/alteração da situação.

Palavras-Chave: Controle Social; Direito à Saúde; Representação Popular; Dispositivos Constitucionais; Alteridade Negada

\section{REFERÊNCIAS BIBLIOGRÁFICAS}

BRASIL, 1986. Conferência Nacional de Saúde, 8은 Relatório Final. Brasília: Ministério da Saúde. , 1988. Constituição, 1988. Constituiçåo da República Federativa do Brasil. Brasília: Senado Federal.

, 1990. Lei $n^{2} 8080$ de 19 de setembro de 1990. Dispõe sobre as condições para a promoção, proteção e recuperação da saúde, a organização e o funcionamento dos serviços correspondentes e dá outras providências. (Lei que se refere à organização enquanto atribuiçōes e competências das várias instâncias no Sistema Único de Saúde). Diário Oficial, Brasília, 20 de setembro de 1990, p. 18.005-9.

COHN, A., 1991. Condições políticas, projetos políticos e construção de estratégia em saúde. Cedec. (Mimeo) , 1982. Pesquisa "Cidadania e Politicas Públicas". Boletins 1, 2, 3, 4. Cedec. (Mimeo)

COHN, A.; NUNES, E.; JACOBI, P. \& KARSCH, U., 1991. A Saúde como Direito e como Serviço. São Paulo: Cortez.

LAZZARINI, M., 1991. Mecanismos de controle social no Código de Defesa do Consumidor. Instituto Brasileiro de Defesa do Consumidor. (Mimeo.)

OLIVEIRA, F., 1990. Os protagonistas do drama: Estado e Sociedade no Brasil. In: Classes $e$ movimentos Sociais na América Latina, (S. Laranjeiras, org.), São Paulo: Hucitec.

SÃo PAULO, 1987. Constituição, 1989. Constituição do Estado de São Paulo, 1989. São Paulo: Assembléia Legislativa.

VALLA, V. V. \& SIQUEIRA, S. A. V., 1989. O centro municipal de saúde e a participação popular. In: Demandas Populares, Políticas Públicas e Saúde, (N. R. Costa; M. C. S. Minayo; C. L. Ramos \& E. N. Stotz, orgs.), vol I, pp. 91-115, Petrópolis: Vozes. 